\title{
LA PARROQUIA DE SAN JOSÉ DE ITURBIDE
}

Elisa García BarragáN

En el estado de Guanajuato, cerca de San Luis de la Paz, existe un apacible pueblo en el que todavía quedan algunas modestas casas finiseculares o de principios de este siglo, con el enmarcamiento de sus vanos en cantera sencillamente labrada; el sitio se llama San José de Iturbide, pero lo que verdaderamente llama la atención en ese lugar, es su gran parroquia, un atractivo revival clasicista de la segunda mitad del siglo pasado, en el que destaca el señorial vestíbulo con columnas cuyos hermosos capiteles corintios recuerdan los del Panteón de Roma.

En suma, todo el repertorio formal empleado en el decorado de esta magnífica construcción, muestra que su autor fue algún arquitecto formado dentro de la escuela clasicista, conocedor a fondo de los estilos griego y romano, así como de sus variantes renacentistas. La pared del vestíbulo, ostenta dos placas, una dedicada al: "libertador Iturbide en el centenario de su entrada triunfal en la capital de la República. Uno de los pocos pueblos que no se han olvidado de su memoria. San José de Iturbide a 27 de septiembre de 1921". Y la otra con información acerca de la edificación de la parroquia en la que entre otras cosas se menciona:

Dirigió la obra el arquitecto D. Rafael Arcaute. En 1873 la continuó el Sr. Pbro. D. Juan José Plaza. A principios de 1875 prosiguió el Sr. Cura D. Domingo Rodríguez y dirigió el maestro D. Valentín López. A fines del mismo año, y durante diez más, el Pbro. Lic. Don Nicolás Campa trabajó hasta casi terminarlo, etcétera.

El nombre del arquitecto mencionado me resulta desconocido, y al revisar más tarde, las Guias del Archivo de la Antigua Academia de San Carlos, ${ }^{1}$ Los catálogos de las exposiciones de la antigua Academia de San Carlos,2 o bien la Arquitectura del siglo xix en México, de

1 Eduardo Báez Macías, Guias del Archivo de la Antigua Academia de San Carlos (1841-1843) (1844-1867), México, UNAM, I.I.E., 1972, 1976 (Serie Estudios y Fuentes del Arte en México, xxxi y xxxv).

2 Manuel Romero de Terreros, Catálogos de las exposiciones de la Antigua Aca. demia de San Carlos de México (1850-1898), México, UNAM, I.IE, 1963 (Serie Estudios y Fuentes del Arte en México, xiv). 
Israel Katzman..$^{3}$ no se menciona a ningún arquitecto apellidado Arcaute, sin embargo no es posible pensar en un autodidacta, a la manera de Refugio Reyes en Aguascalientes. Dejó el pueblo, preguntándome por qué y cuándo se le puso el nombre de San José Iturbide, y quién fue el misterioso arquitecto que logró tan interesante fábrica. Decido volver para interrogar al párroco o a los vecinos del lugar, y esta segunda visita produce buenos frutos, ya que la gente de San José es amable. El párroco me informa que acaba de llegar al pueblo, pero que tiene noticias de que existe una breve historia de ese sitio en la que se habla de la construcción de la parroquia y que quizás se encuentre en la biblioteca municipal. Las indagaciones me llevan a entrevistarme con el actual presidente municipal del pueblo, doctor Roberto de la Vega Velázquez, un joven egresado de la UNAM. Él y su secretaria, Luz María Arvizu Garduño, me proporcionaron una copia de los apuntes sobre la historia del pueblo, los cuales resultan valiosísima información ya que durante la lucha cristera, los archivos del pueblo fueron quemados. Asimismo, me indican que en la notaría cercana a la parroquia, probablemente se encuentren más referencias y algunos retratos de los constructores y de los sacerdotes que se preocuparon por colectar el dinero para esa edificación. El notario también es nuevo en el pueblo, pero los retratos por sí solos, resultan reveladores; allí están el del distinguido arquitecto decimonónico Ramón Rodríguez Arangoiti, quien fuera, podemos decir, el arquitecto del emperador Maximiliano, magnífico retrato al óleo que al ser descolgado (por el fotógrafo Rafael Rivera), en la parte posterior ostenta el nombre del arquitecto, la fecha "Iturbide, Enero 12 de 1883" y la firma "Felipe S. Gutiérrez pintó".

Otro muy buen retrato el del párroco Campa, a cuyo empeño se debe la construcción del templo; es probablemente de Felipe S. Gutiérrez, aunque no está firmado, y otro más el del cantero Valentín López, que aparte del interés pictórico, tiene el de ser un documento histórico, pues poquísimas veces se da crédito a los artesanos $\mathrm{y}$, mucho menos, se les considera dignos de figurar en un cuadro. Posee varias calidades: es de buena factura, y muestra a un tipo muy mexicano, que al atractivo de su personalidad e indumentaria, añade la composición con el sarape, el sombrero y los utensilios para labrar la cantera; este curioso

3 Israel Katzman, Arquitectura del siglo xIx en México, México, UNAM, CIA., 1973. 
retrato tampoco está firmado y quizá es de Felipe S. Gutiérrez a quien tanto atrajeron los tipos populares y el que seguramente no hubiera desdeñado firmarlo. En la parte posterior del retrato del padre Campa se lee:

Retrato del maestro albañil y cantero don Valentín López ejecutor de los proyectos que dibujó el ingeniero don Ramón Rodríguez Arangoiti para la cúpula y fachada de esta iglesia parroquial y autor y ejecutor de la bóveda plana del pórtico de la misma iglesia.

Es pertinente antes de mencionar a Rodriguez Arangoiti y a su importante edificación, el dar algunas noticias sobre la historia de este peculiar pueblo, uno de los poquísimos o quizá el único que solicitó cambiar su nombre por el del caudillo independiente Iturbide. Es posible conocer esos antecedentes gracias a la acuciosa labor de uno de sus vecinos, José Luis Morelos, quien recogió datos que permiten co $^{-}$ nocer someramente la vida de San José de Iturbide desde sus origenes.

La villa es de muy reciente fundación; data de la segunda mitad del siglo xviII, y se edificó en terrenos de las haciendas de San Diego, San Jerónimo, Charcas y sobre todo del Capulín, en el costado occidental de la Sierra Gorda. Su primer nombre fue Casas Viejas, pues parece que al tiempo de ser fundada todavía quedaban vestigios de algún asentamiento notable prehispánico, ya que en esos terrenos se encontraron abundantes muestras de cerámica y armas de pedernal. Primero se $\epsilon$ stableció en ella una ayudantía de parroquia, que se elevó en julio de 1874 a "curato de colación canónica".

La extensión y habitantes de Casas Viejas no aumentaron en varios años, y para 1810 "su congregación estaba compuesta por veinte viviendas, en forma de cuadrilila sin orden regular"; el censo no excedía de cien habitantes en la congregación y seis mil en la comarca, y du" rante la conflagración revolucionaria, el pequeño lugar casi fue arrasado, quedando en pie únicamente su pequeña parroquia; pero à partir de 1820 en que algunas de las haciendas que la formaron empezaron a dividirse en arrendamientos parciales, el valle se cubrio de semente. ras y aumentaron los habitantes. En abril de 1822 el pueblo solicitó por conducto de la Regencia del imperio mexicano de Iturbide, que la población se erigiera en villa o que por lo menos se le agraciara con el título de pueblo, "ofreciendo pagar el valor del fondo legal y ejidos que se le señalaron". La solicitud para que fuera villa se repitió en marzo de 1827, dirigida a la legislatura del estado de Guanajuato; se 
insistió sobre lo mismo en 1829, 1830 y 1834; y el ayuntamiento del lugar siguió instando sobre esto a medida que territorio y población fueron creciendo.

En 1847, al estallar la revolución de Sierra Gorda, los generales Anastasio Bustamante y José López Uraza, encargados de aplacar la rebelión, establecieron su cuartel general en Casas Viejas en donde contaron con la ayuda valiente y heroica de los vecinos del lugar. Al triunfo del ejército y como merecido premio a la bravura y patriotismo de los habitantes de Casas Viejas, el Cuerpo Legislativo de Guanajuato expidió el decreto:

marcado con el número, 100 iniciado por el Gobierno, concediendo a Casas Viejas el título de Villa con la denominación de San José de Iturbide, como recordatorio de que en ese sitio estuvo Iturbide con sus tropas del 22 al 25 de junio de 1821, pues pensaba partir de ahi para estrechar el sitio de Querétaro.

Según informa Niceto Zamacoiz, y debido a eso el "Ayuntamiento de la Congregación de Casas Viejas solicitó el 3 de marzo de 1834 que el pueblo fuera declarado Villa con el nombre de San José de Iturbide, lo cual le fue concedido hasta el 9 de octubre de 1849".

La denominación de villa y el cambio de nombre movieron a los vecinos a mejorar el lugar; sin embargo, los problemas por los que atravesaba el país y las exigencias del gobierno central -sobre todo durante las gestiones del general don Antonio López de Santa Annafueron causa de que la villa se estancara y aun se degradara hasta la llegada, en mayo de 1862, del general don Miguel María Echegaray, investido de facultades gubernativas y militares. El general Echegaray de inmediato recorrió la población $y$, al constatar el estado de abandono en que se encontraba por el desaseo de calles y edificios, ordenó que éstos fueran enjarrados, pintados y limpiadas las calles. repartió equitativamente el gasto entre los habitantes, y también instaló el alumbrado público empleando a su tropa en este menester. La población se embelleció, caso insólito gracias a una orden militar (datos escritos por José Luis Morelos el 13 de julio de 1871).

Al crecer la población se sintió la necesidad de construir una nueva iglesia: la Casa de Loreto, pues la antigua parroquia resultaba de cortas dimensiones. Finalmente, se decidió tirar las paredes de la vieja parroquia y cimentar una nueva de mayor tamaño. Las imágenes que albergaba el templo fueron depositadas en casas particulares, con bas- 
tante inquietud y preocupación por parte de los vecinos. En adendas a su primer escrito, Morelos informa que, en enero de 1873 a expensas de varios vecinos, "comenzaron a construirse tres columnas para los arcos del cuerpo de la Iglesia, siendo los primeros contribuyentes Don Nicolás González, Don Rómulo Romero y Doja Catarina Mendieta”.

En ese mismo año, ya arreglada la villa con su plaza mayor, casas consistoriales, escuelas, etc., el señor Rómulo Romero, síndico del Ayuntamiento, adquirió un reloj público e introdujo el agua a la población; además, se estableció la línea telegráfica que comunicaba a San José de Iturbide con San Miguel Allende, poniéndose el primer parte telegráfico el 29 de diciembre de ese año, 8 días después de la muerte del bachiller don Cipriano Rodríguez, quien trabajara incansable en ayuda de la construcción del nuevo templo de la villa y de la parro. quia, por lo que, a mediados de enero de 1874, el presbitero don Juan José Plaza se hizo cargo de esta obra.

La narración antes mencionada señala que el mismo mes se bendijo el arco de la portada de la parroquia; el 21 de julio del mismo año, el segundo arco en la misma portada "del lado de la epístola, el primero de agosto, el tercer arco de la misma portada, el del lado del evangelio". Mientras tanto, el nuevo templo de la casa de Loreto se bendecía el 11 de diciembre de 1874, y al día siguiente se celebraba la primera misa solemne.

Parece que a partir de este momento, la narración escrita por José Luis Morelos, vecino de la villa desde 1824, y desde entonces director de los juzgados populares y secretario de $\mathbf{H}$. Ayuntamiento, se vuelve confusa; quizá Morelos se encontraba ya enfermo, pues muere un año después, el 26 de enero de 1876.

Ese desconcierto en los datos vertidos por José Luis Morelos los señala Jesús María Loyola, quien los transcribe a su vez en 1951, de otros copiados en agosto de 1921, por un habitante de esa población que se firma J.M.Z.R.

Sin embargo, la confusión cada vez es mayor en estos apuntes que se han venido glosando. Se confunden las construcciones de las dos iglesias, la Casa de Loreto y la Parroquia; respecto a esta última, se habla de los arcos de la portada, inexistentes; se menciona indistintamente a. Rafael Arcaute como constructor de ambas, y se señala que el 19 de julio de 1875 se hizo cargo de la dirección de la obra de la parroquia el maestro Valentín López. Es lógico que de toda esa anarquía en la 
relación provengan los errores vertidos en la placa del vestíbulo, que con muy buena fe mandó colocar el presbítero Filiberto Carrillo G., placa que aparte de mostrar el amor de dicho presbítero hacia su parroquia, despertó mi curiosidad para hacer averiguaciones sobre un arquitecto desconocido, de magnífica formación (¿Arcaute?), y posteriormente sacar a la luz una importante obra de Ramón Rodríguez Arangoiti, ya que la parroquia es un buen ejemplo de la calidad de la arquitectura mexicana en el último tercio del siglo, no sólo en la capital, sino también en la provincia.

La parroquia de San José de Iturbide, con su grandioso vestíbulo neoclásico que parece haber sido edificada con un gran rigor historicista, teniendo en mente las construcciones de la antigüedad clásica, al ser observada en su vocabulario formal, denota que, en efecto, los elementos tectónicos son de origen griego y de orden corintio, pero que su autor, Rodríguez Arangoiti, de espíritu ecléctico -como corresponde a un hombre de su época-, prefirió tamizar la rigidez historicista, e interpretar con cierta libertad esas formas arcaicas, mezclándolas con elementos renacentistas, y si bien acróteras, series de ovos, dentículos, ménsulas, coronamientos de vanos con doble voluta, cerrados por conchas o especie de antemas, son usadas profusamente, las licencias con que Arangoiti los maneja, hacen sumamente atractiva esa interesante fachada que conserva en el interior del vestíbulo una serie de nichos adintelados, cuyo destino sería -según las referencias de la historia del pueblo- el de albergar estatuas de santos, y que en la actualidad producen una curiosa impresión en el espectador, al enfrentarse a toda una serie de vanos adintelados cegados, que poco recuerdan los nichos tradicionales.

La fachada está compuesta por dos cuerpos, rematado el segundo, también, por un frontón; al examinar este segundo cuerpo, se presenta la duda de si debería estar culminada por dos torres, pero de acuerdo al espíritu clásico, y si se piensa en edificios diseñados en ese estilo, se tiene la seguridad de que los remates son los decididos por Arangoiti. La conjetura respecto a las torres se debe a la colocación de dos torres en la parte posterior construidas hace pocos años, en 1941, según afirma la placa explicativa de la portada, las que estorban y modifican el efecto que Arangoiti quiso dar a ese conjunto clásico, pues si bien este arquitecto no tuvo la intención de apegarse arqueológica- 
DOI: http://dx.doi.org/10.22201/iie.18703062e.1983.52.1182

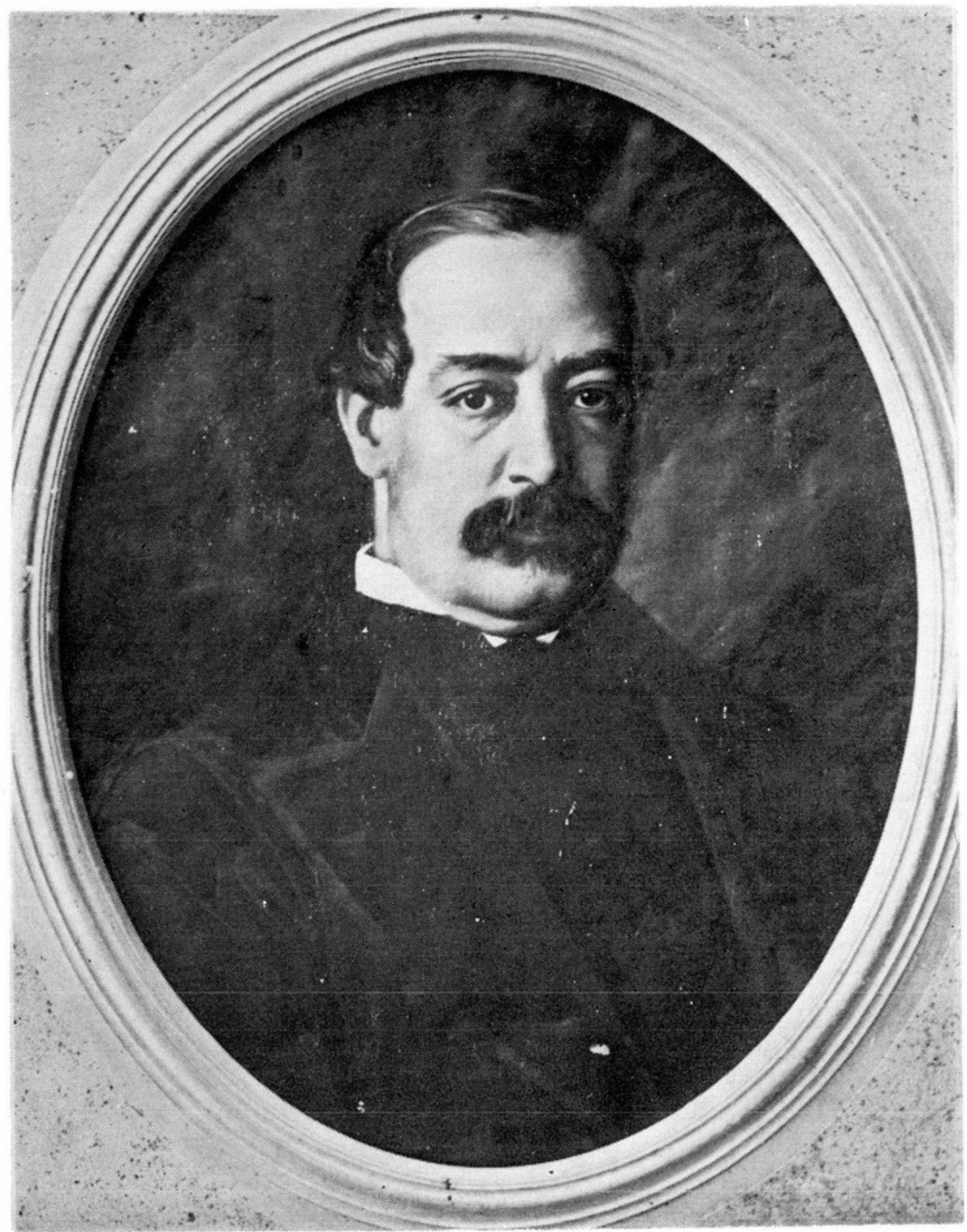

Figura I. Felipe S. Gutiérrez. El arquitecto Ramón Rodriguez Arangoiti. 1883. Foto Rafael Rivera. 
DOI: http://dx.doi.org/10.22201/iie.18703062e.1983.52.1182

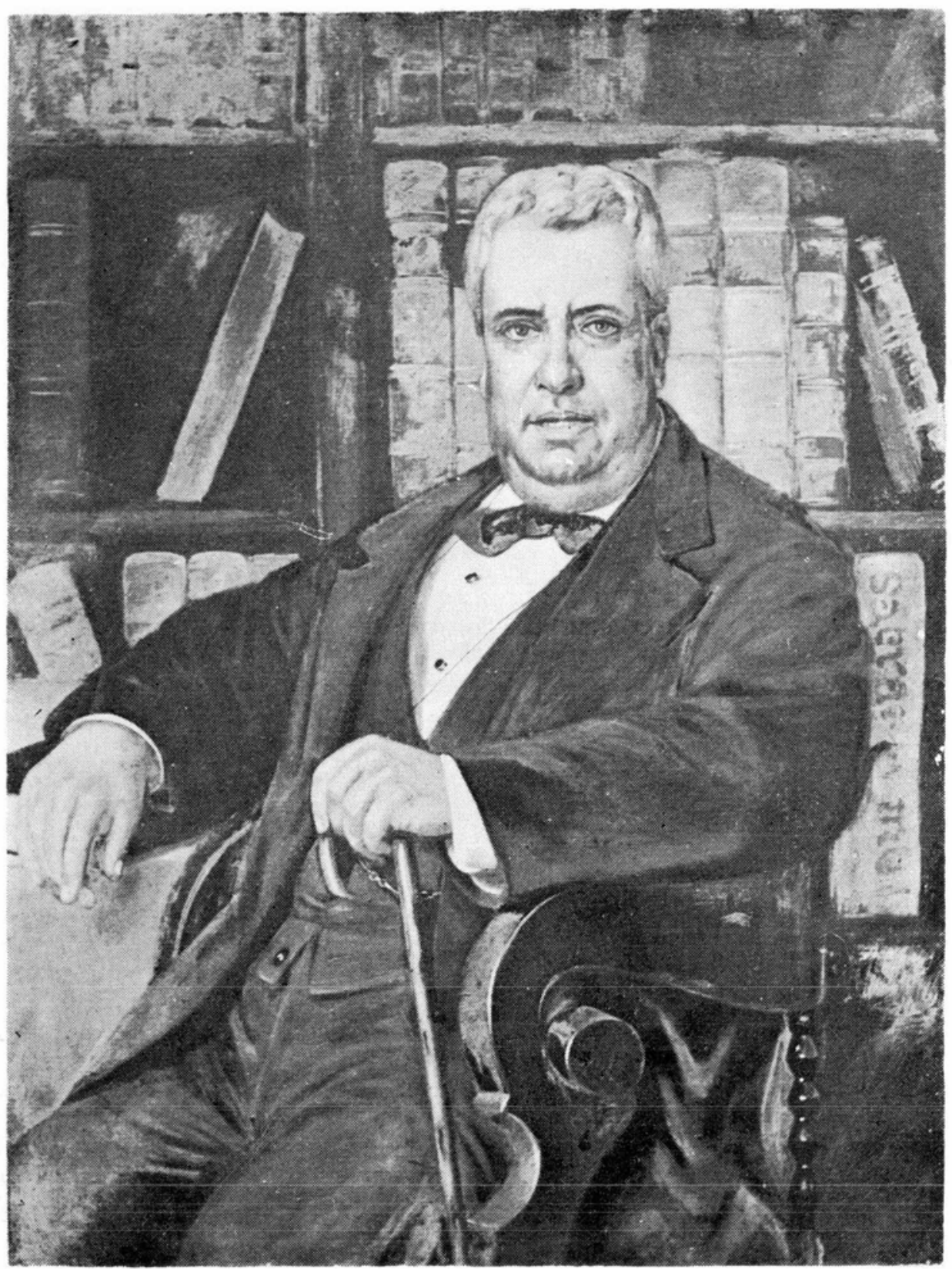

Figura 2. Retrato del Pbro. Lic. Don Nicolás Campa. Foto Rafael Rivera. 
DOI: http://dx.doi.org/10.22201/iie.18703062e.1983.52.1182

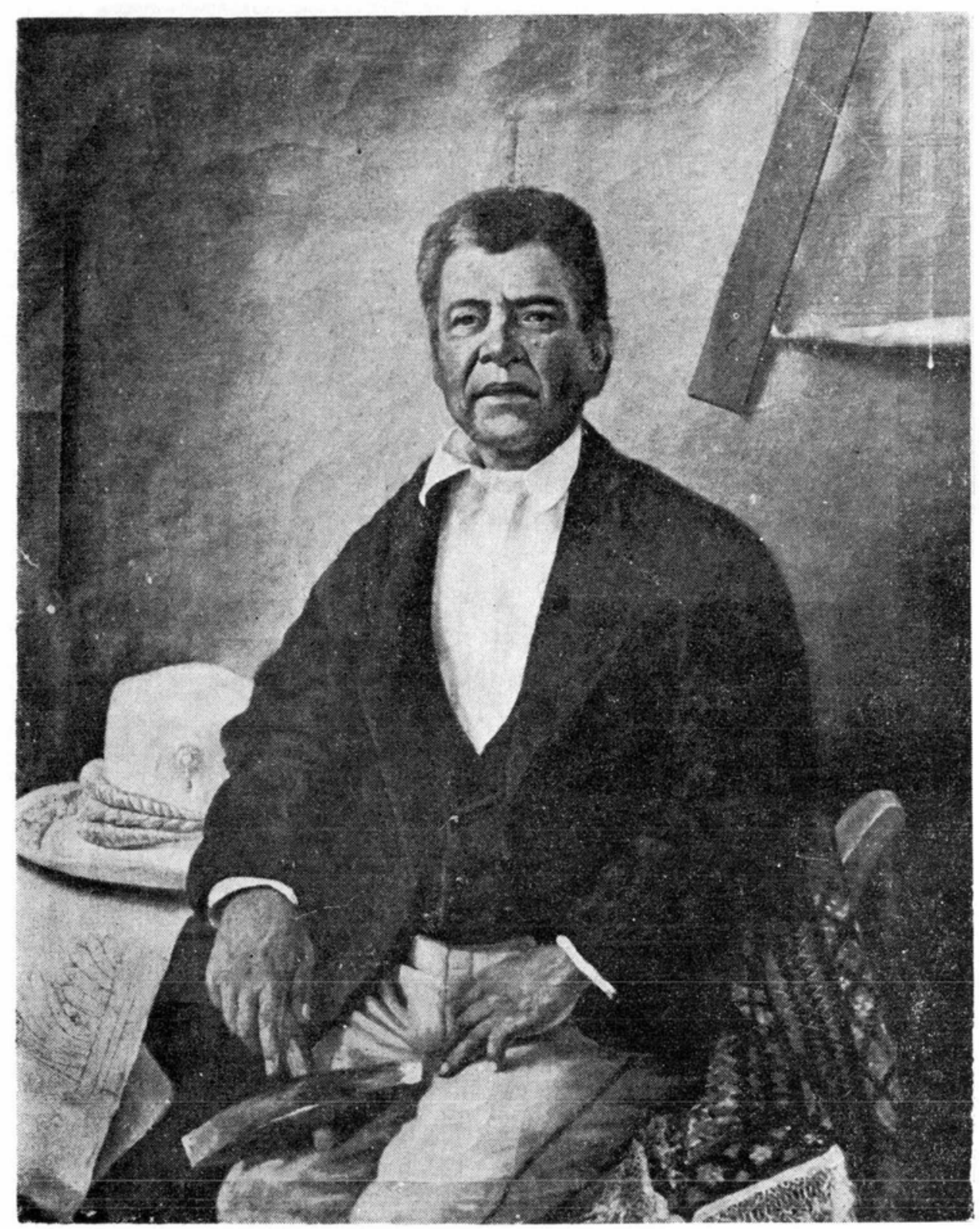

Figura 3. Retrato del maestro cantero Valentín López. Foto Rafael Rivera. 


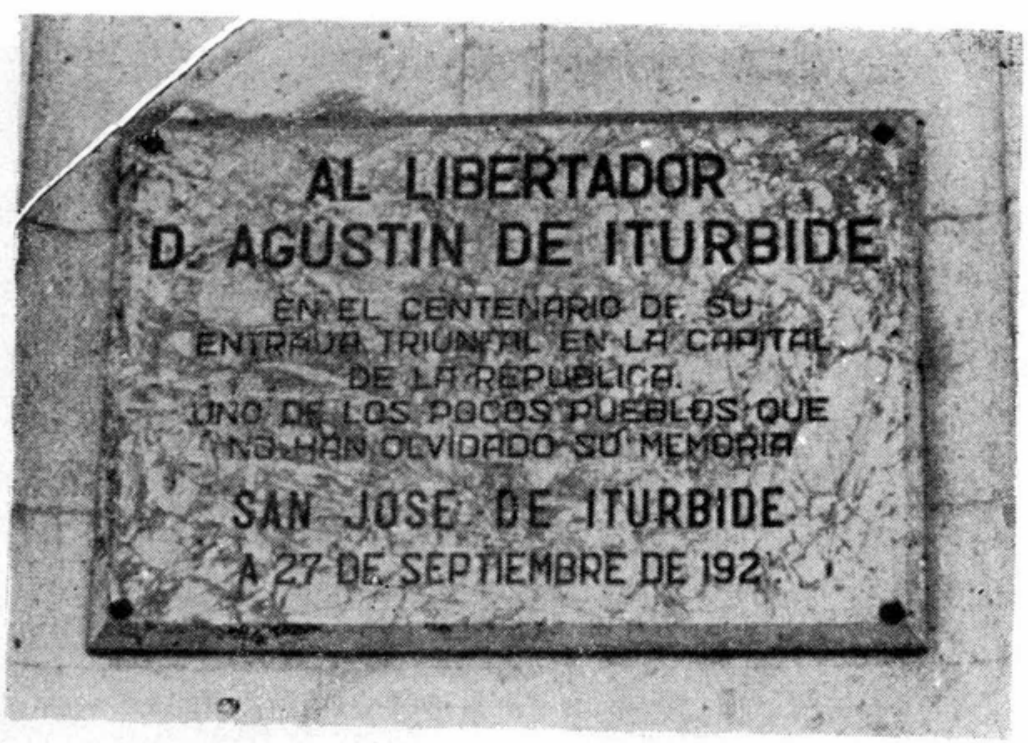

Figura 4. Placa conmemorativa.

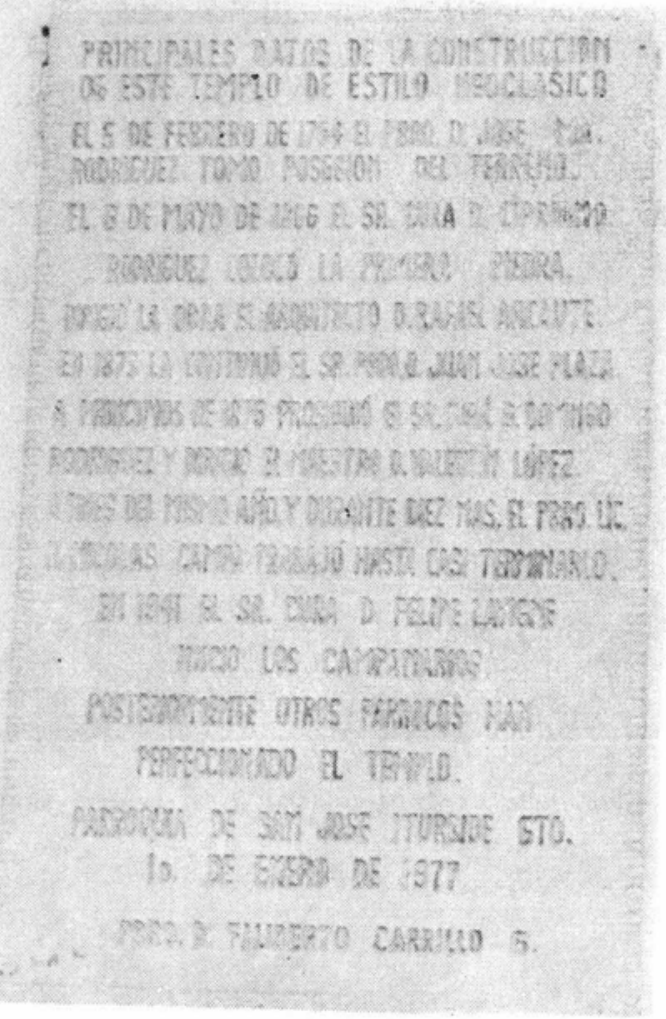

Figura 5. Placa con datos de la construcción. 
DOI: http://dx.doi.org/10.22201/iie.18703062e.1983.52.1182

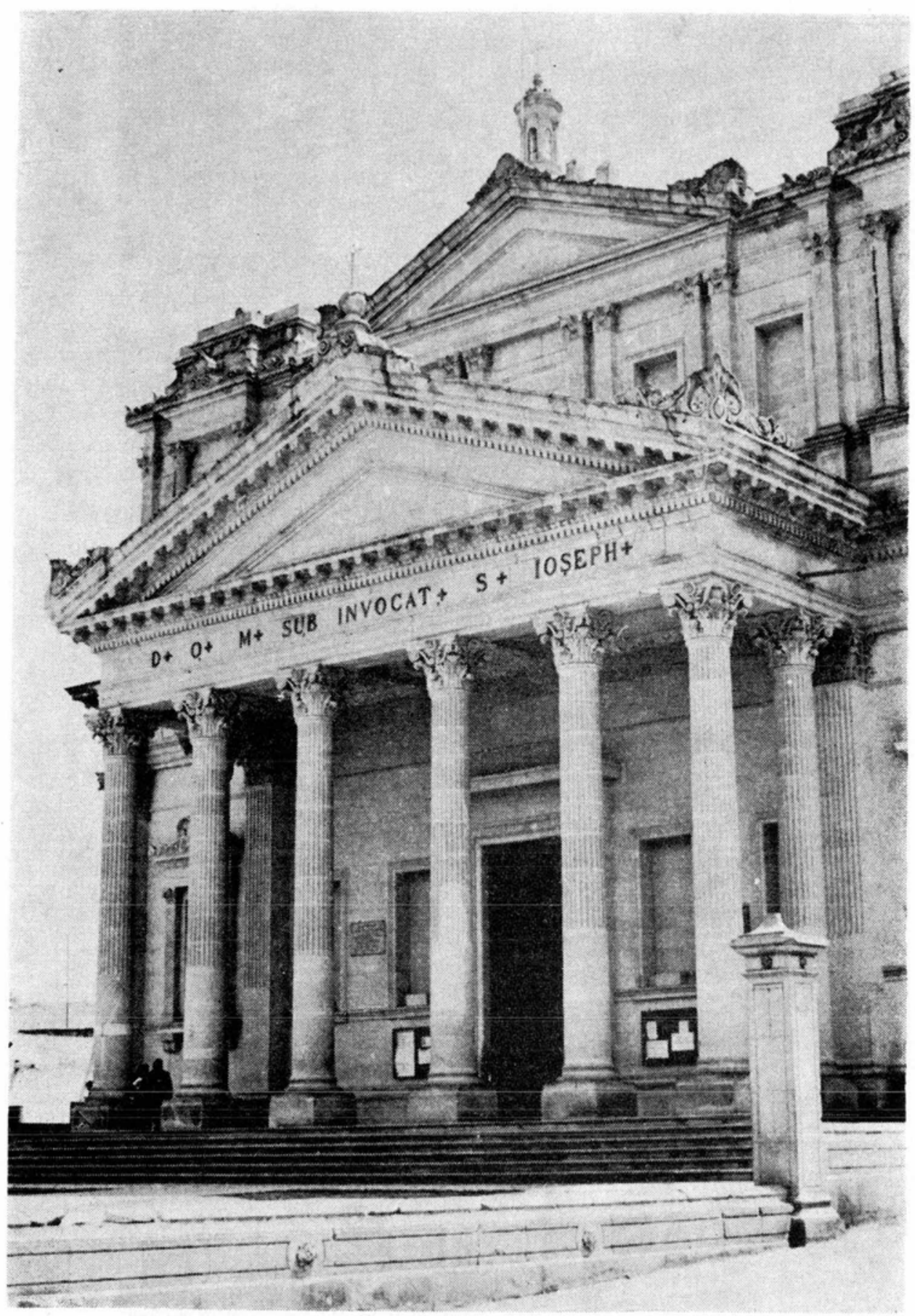

Figura 6. Fachada de la parroquia de San José de Iturbide. 
DOI: http://dx.doi.org/10.22201/iie.18703062e.1983.52.1182

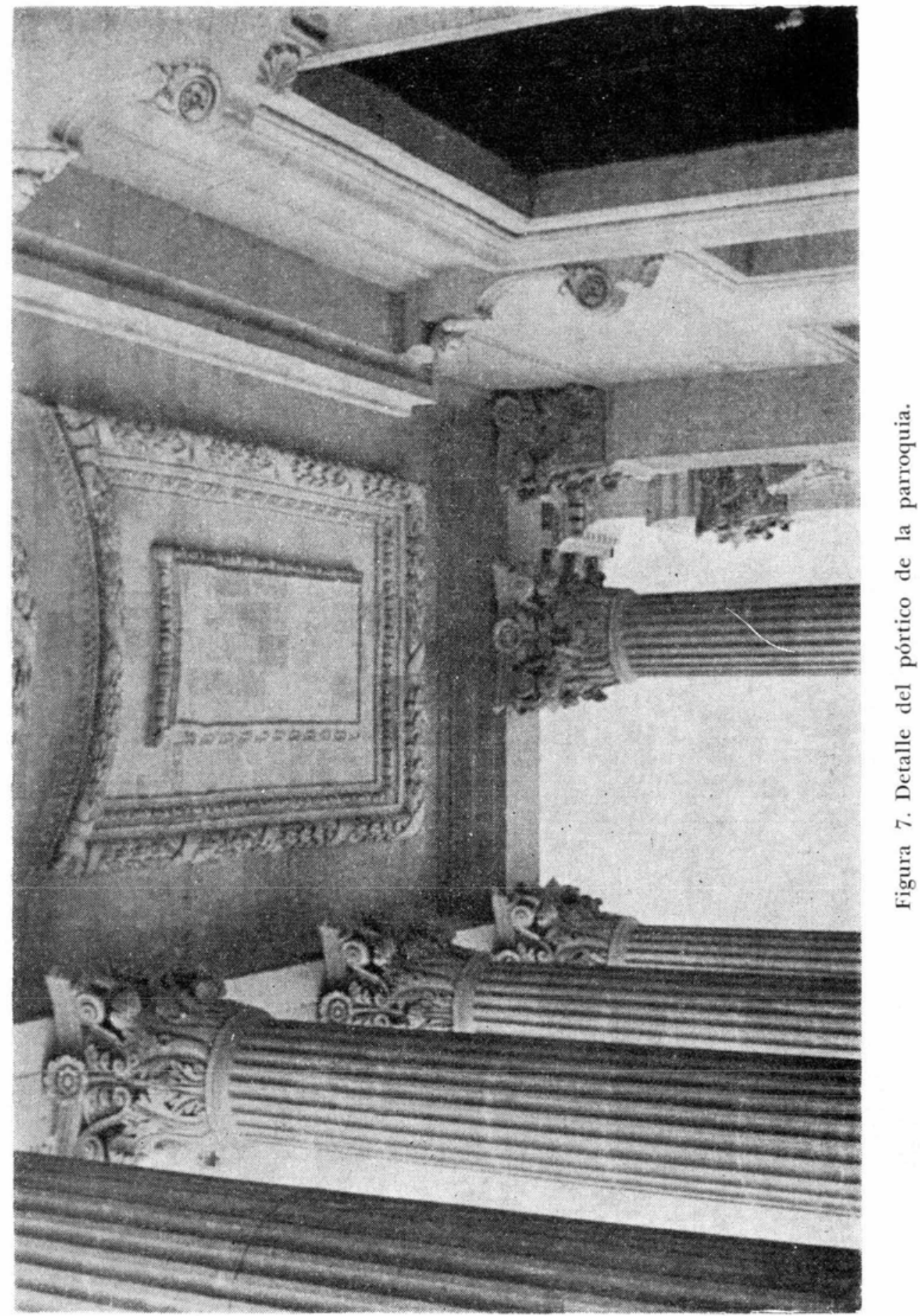


DOI: http://dx.doi.org/10.22201/iie.18703062e.1983.52.1182

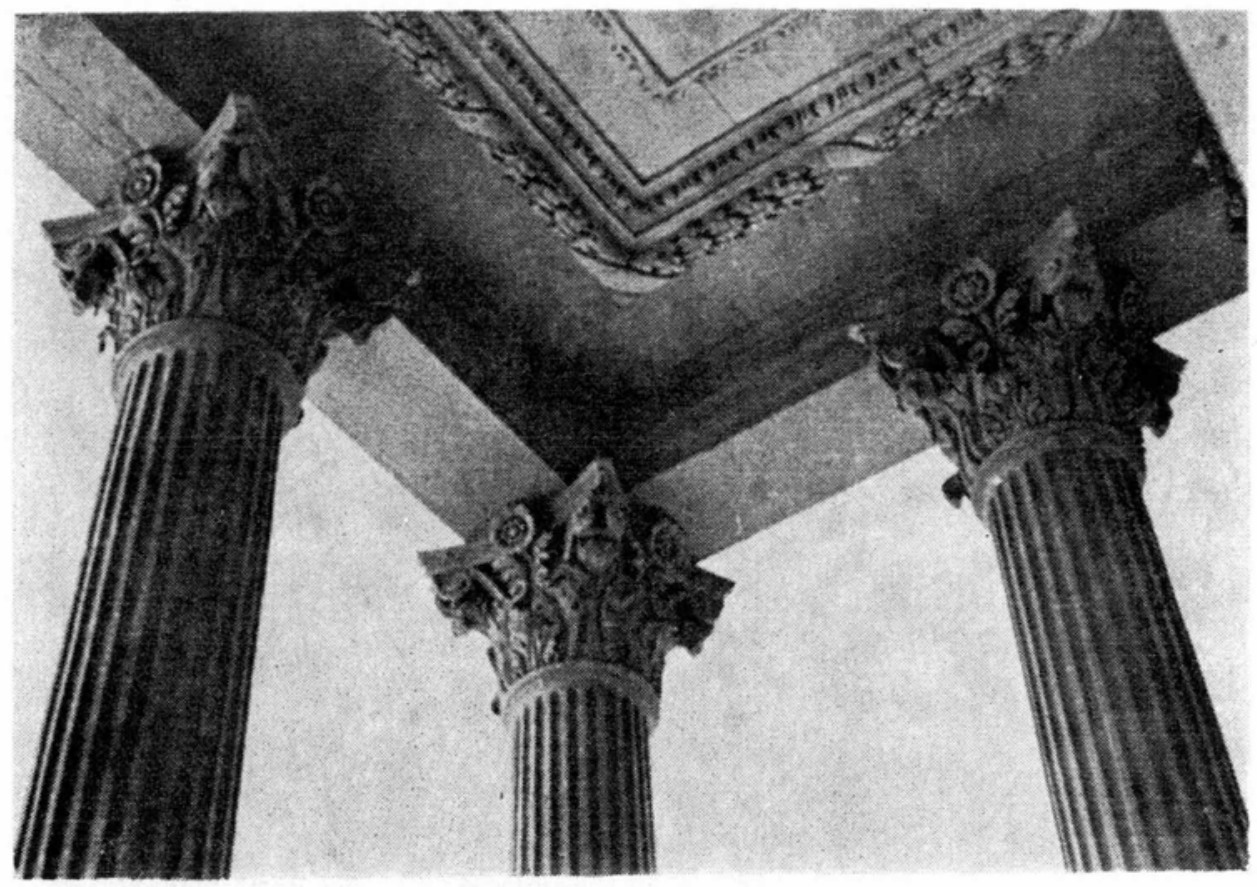

Figura 8. Detalle del pórtico de la parroquia.

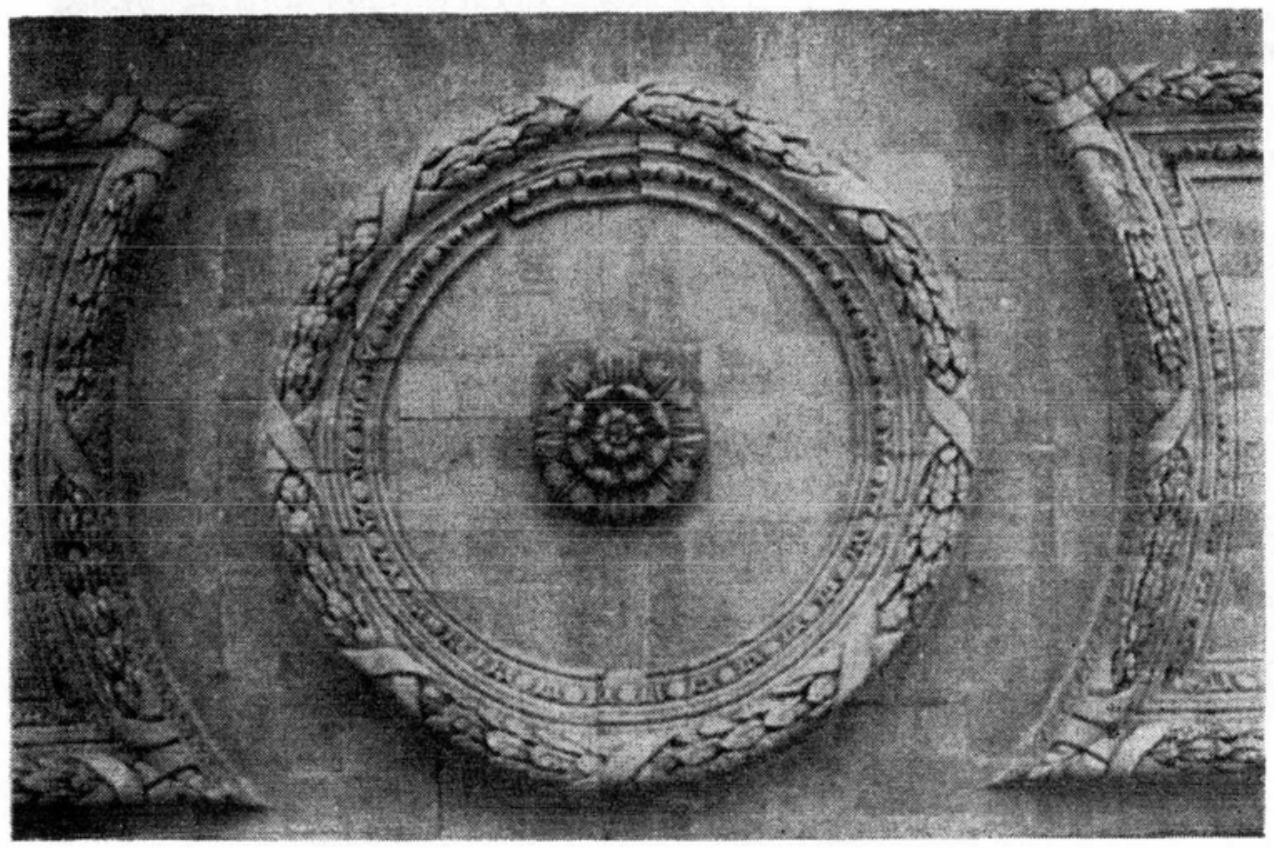

Figura 9. Ornamentación del techo del pórtico. 
DOI: http://dx.doi.org/10.22201/iie.18703062e.1983.52.1182

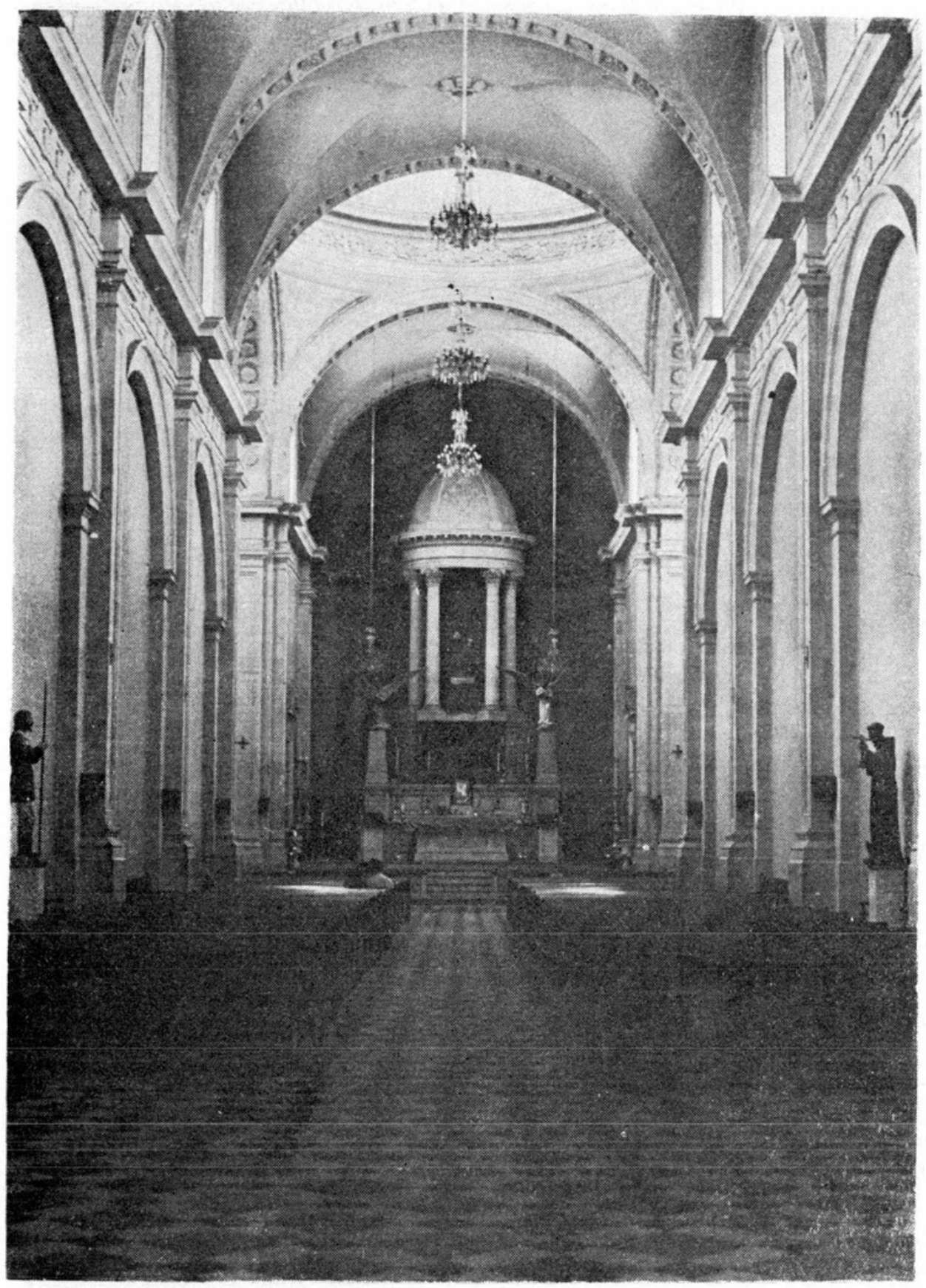

Figura 10. Nave de la parroquia. 
DOI: http://dx.doi.org/10.22201/iie.18703062e.1983.52.1182

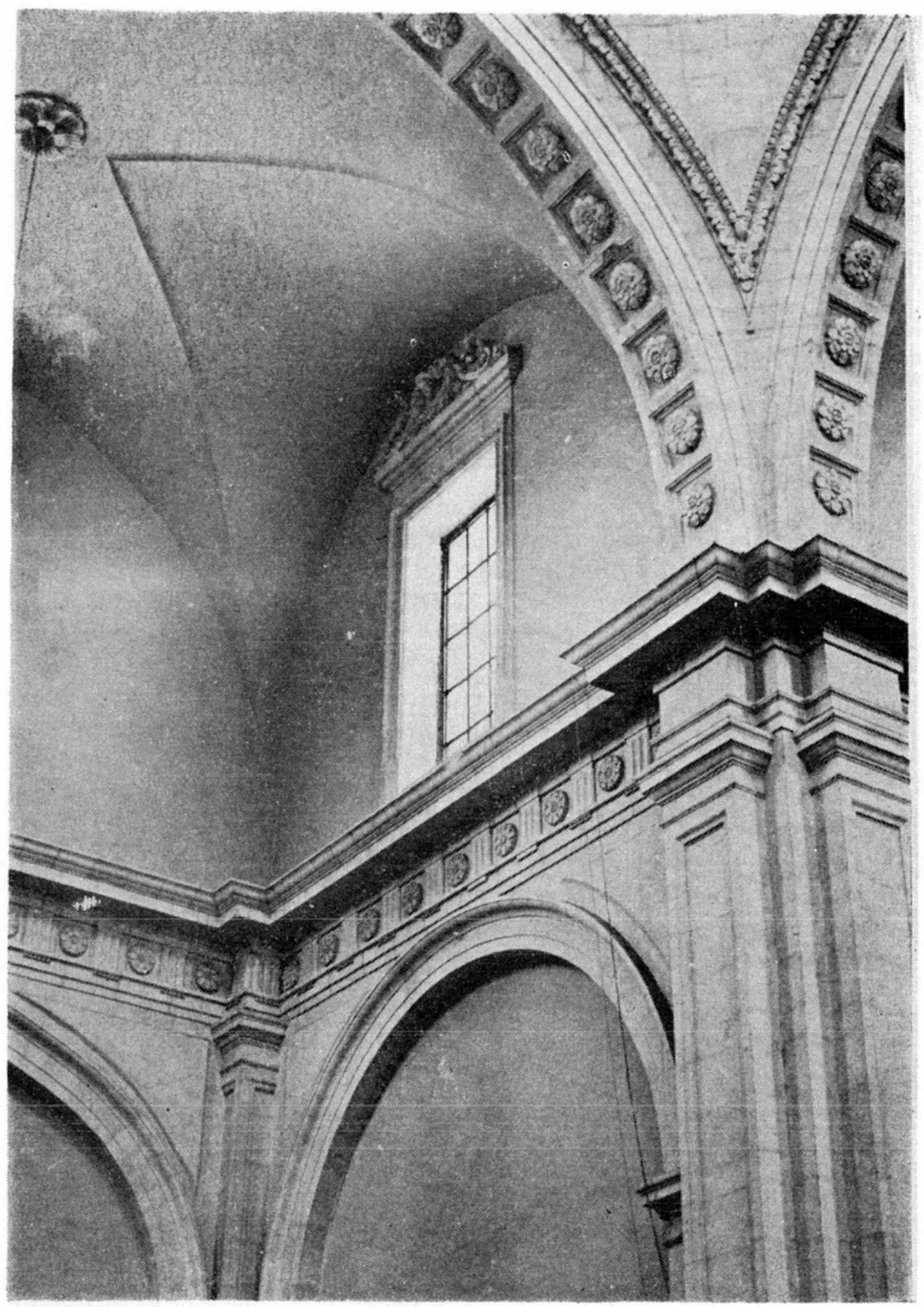

Figura 11. Detalle de la ornamentación interior. 
DOI: http://dx.doi.org/10.22201/iie.18703062e.1983.52.1182

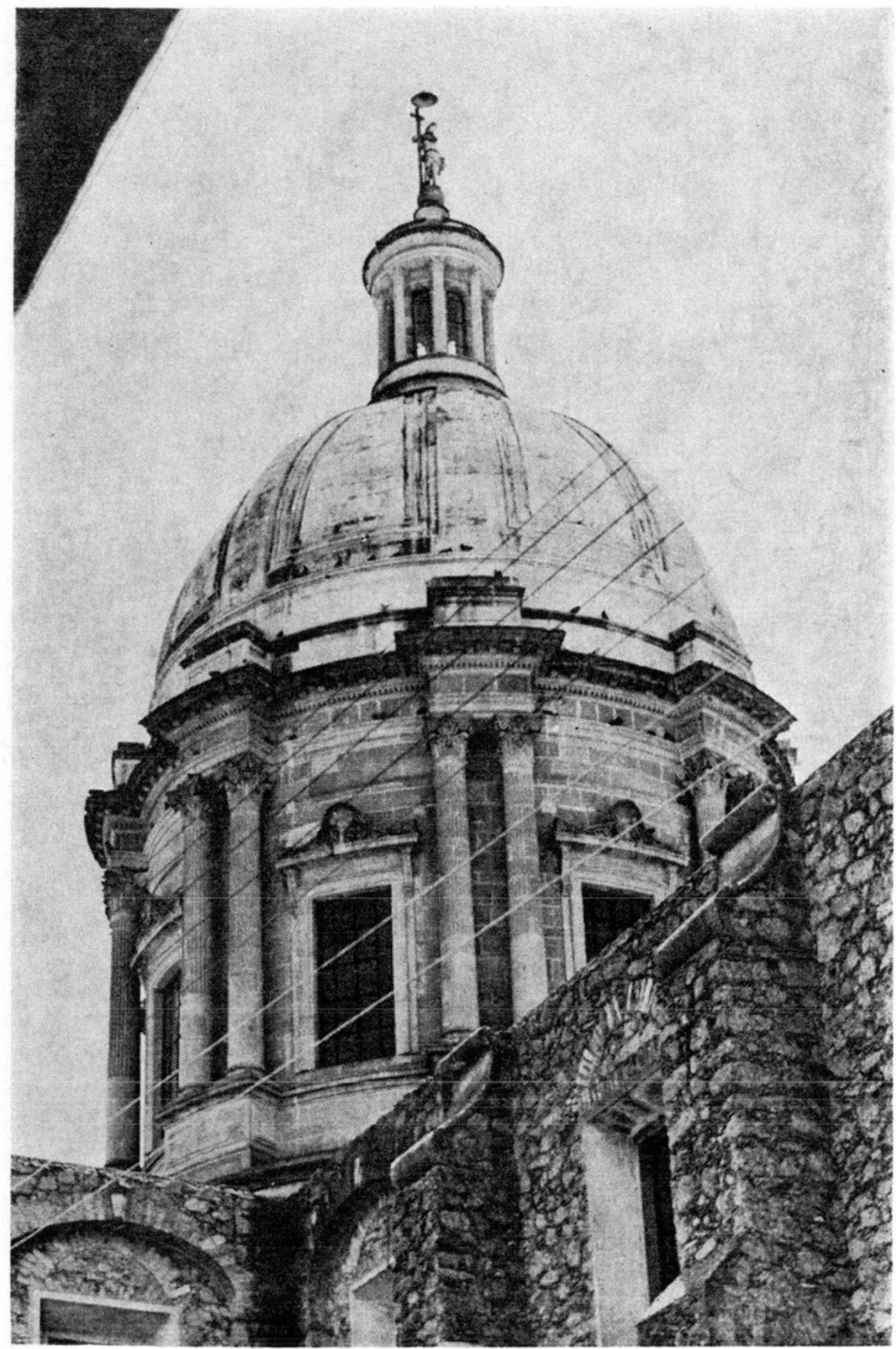

Figura 12. Cúpula de la parroquia. 
DOI: http://dx.doi.org/10.22201/iie.18703062e.1983.52.1182

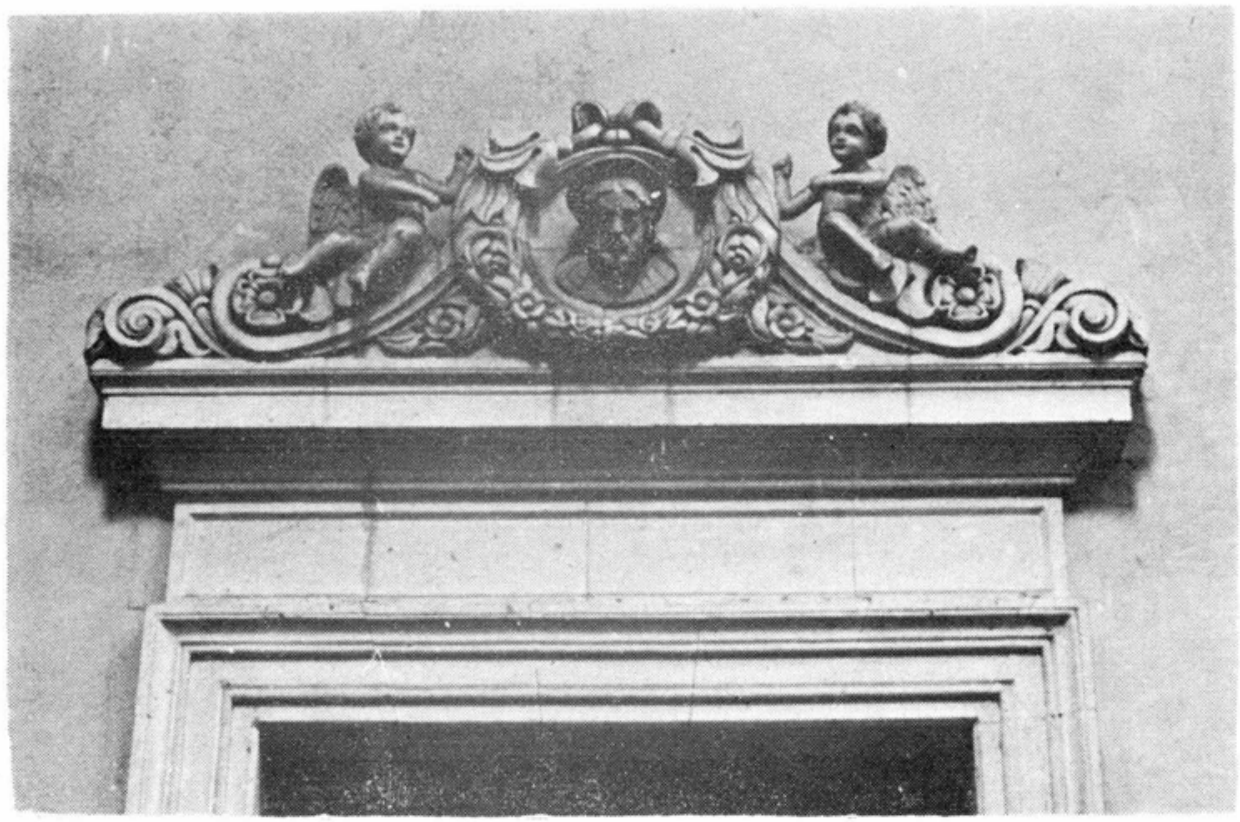

Figura 13. Remate de un vano del interior.

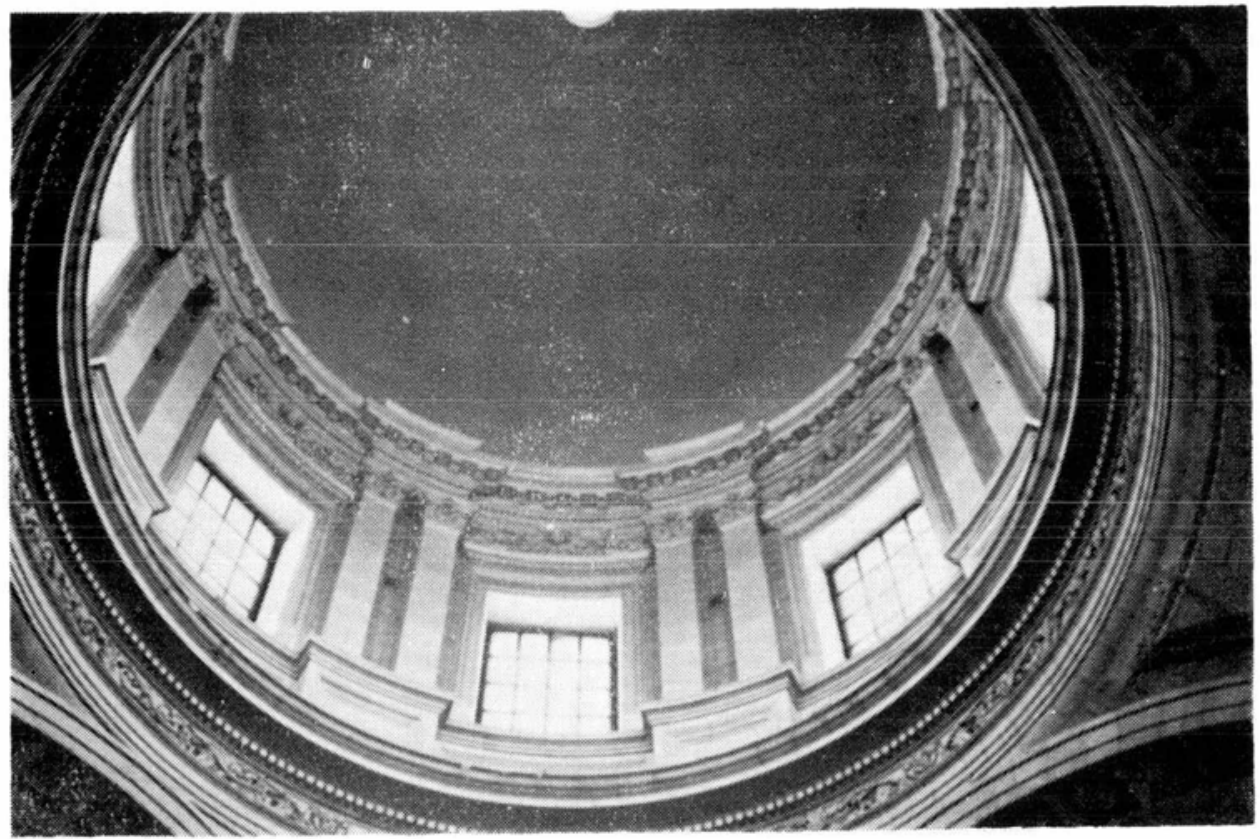

Figura 14. Tambor de la cúpula. 
DOI: http://dx.doi.org/10.22201/iie.18703062e.1983.52.1182

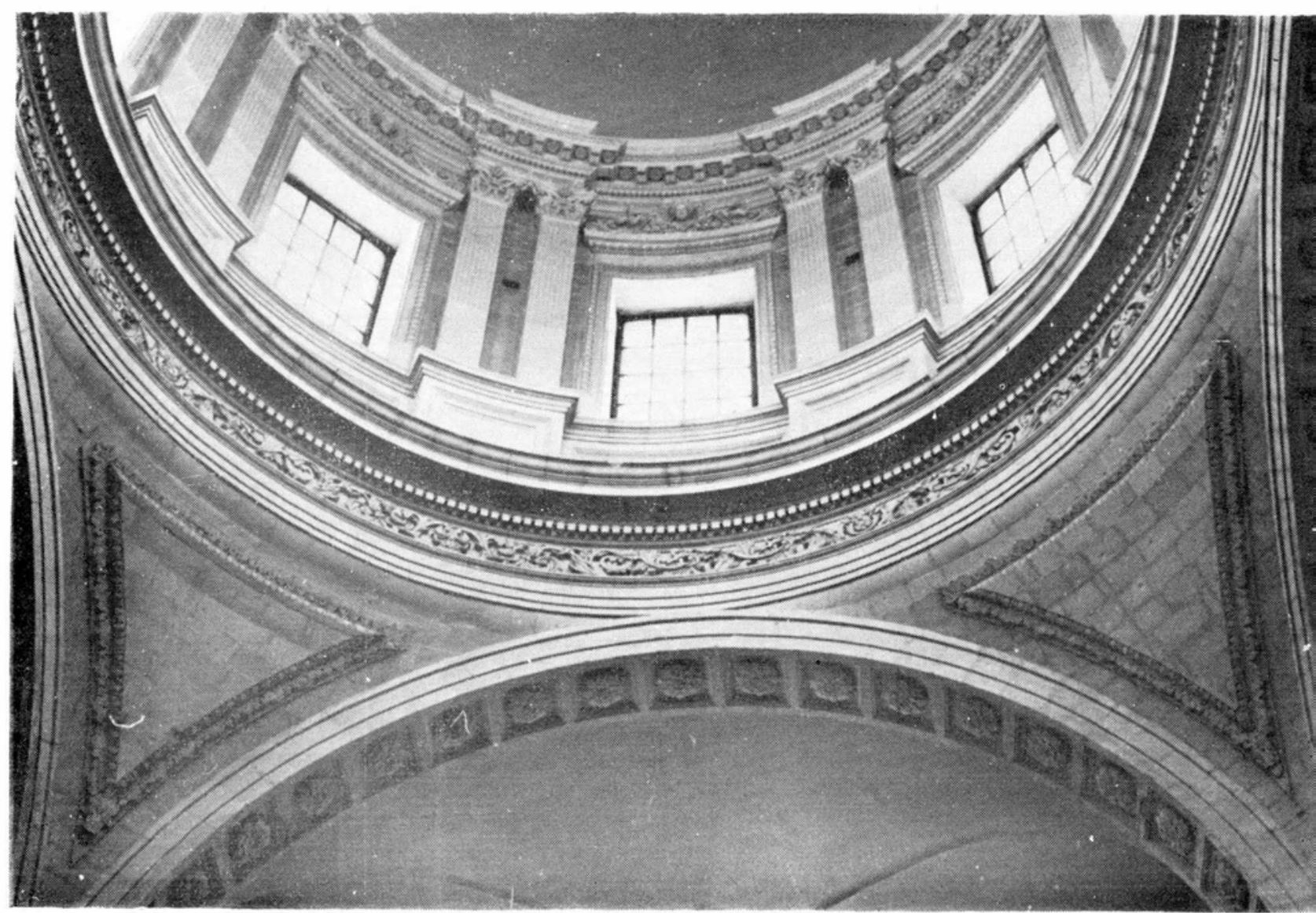

Figura 15. Detalle del tambor. 
mente a los pórticos griegos. sí, la solución lógica para el tipo de edificación que realiza es el remate diseñado por él.

Resulta claro que el lenguaje ornamental es clásico, y que la mente que lo utiliza es predominantemente laica y afrancesada, y debido a ello organiza todos esos elementos de una manera muy racional, empleando un razonamiento a la francesa y no a la griega.

La formación europea de Arangoiti, sobre todo en su estadía en Francia, lo imbuye de un pensamiento cívico que va acorde con el espíritu neoclásico empleado en la parroquia, a la que el arquitecto le da la apariencia laica de un teatro.

En el interior, la gran nave de la iglesia está decorada en su derredor con el friso dórico de triglifos y metopas ornamentadas con rosetones; los demás elementos decorativos son estilizaciones vegetales: cintas de follaje, guirnaldas y festones; de igual manera, con gxan acierto Rodríguez Arangoiti, en los remates de los vanos interiores, maneja las formas a manera de frontones con roleos, en los que enmarcadas con guirnaldas aparecen las efigies de Jesús y pequeños angelillos acomodados en los roleos, a la manera renacentista.

En cuanto a la cúpula, muy esbelta, recuerda al primer neoclásico, al de Tresguerras. En ella se logró una buena solución en el gran tambor, que por fuera tiene columnas pareadas y por dentro correspondientes pilastras, medida que se remonta a Miguel Ángel y que fue tan del gusto de los primeros arquitectos neoclásicos como el mencionado Tresguerras.

Volviendo a Rodríguez Arangoiti, poco se sabe sobre su vida y actividades; Katzman y Eduardo Báez han publicado sobre él someros datos. Katzman es el primero en mencionar su intervención en la parroquia de San José de Iturbide, indicando que la termina en 1877-78. y que "en obras como la iglesia de San José de Iturbide demuestra ser uno de los mejores arquitectos clásicos". 4

Pero es un contemporáneo del arquitecto Arangoiti, el arquitecto e ingeniero Manuel F. Álvarez, quien puntualiza la participación de Arangoiti en esa fábrica.

Alvarez y Arangoiti sostuvieron una estrecha amistad. En alguno de sus escritos Alvarez comenta que posee varios de los dibujos y pro. yectos del segundo, y además, en su libro $E l$ doctor Cavallari y la carrera de ingeniero civil en México, en la sección dedicada a dar a co-

4 Israel Katzman, op. cit., p. 292 , 
nocer datos biográficos de sus compañeros más sobresalientes en la Academia de San Carlos, respecto al templo de San José de Iturbide afirma:

En 1877 y mayo de 1878 Rodríguez proyectó y dirigió la iglesia de San José de Iturbide en el Estado de Querétaro de la que estaba encargado su amigo el padre Campa quien con verdadero amor y dedicación llevó a cabo tan importante obra; la iglesia tiene una fachada de veinticuatro metros de longitud por 12 de altura; dieciocho en el frontón; una cúpula de doce metros de diámetro; siete metros de altura la linternilla; y la cúpula 29.5, y desde el piso cuarenta y siete metros. ${ }^{5}$

Aparte Álvarez se refiere a muchas otras de las obras de este arquitecto, haciendo hincapié en "los sólidos principios del arte clásico" que poseía, e indica que: "de su estancia en París, Rodríguez se creó su segunda manera de sentir, el neo-greco, que en obras y edificios se empleaba y que sentía con tanto gusto".

Para avalar las afirmaciones acerca de la preferencia de Ramón Rodriguez Arangoiti hacia lo clásico, resulta oportuno mencionar la formación de este arquitecto, que de la carrera militar y después de una valiente intervención en la defensa del castillo de Chapultepec, en 1847, y de sufrir prisión por los americanos, aparte de otras incursiones en la milicia, dado su amor a las bellas artes, se inscribió en los cursos de arquitectura en 1851, y logró al año siguiente una pensión en dicha escuela. Es posible rastrear sus progresos y pasos dados en su trayectoria por la arquitectura gracias a la Guía del Archivo de la Academia de San Carlos y a las orientaciones que su autor da en torno a este arquitecto; y así se sabe que el 30 de diciembre de 1853 concursa para conseguir una pensión en Europa. En 1854 sale rumbo a París, acom. pañado por el joven escultor Epitacio Calvo, ya que ambos obtuvieron el 15 de junio la pensión para trasladarse a estudiar a Roma. Antes de llegar a su destino final, conocen París. La Ciudad Luz debió haberles causado un gran impacto, pues años más tarde Arangoiti pasaría una larga temporada en esa capital. Mas volviendo a su estancia en Roma, en la Guia del Archivo de la Academia aparecen constantes menciones de los adelantos y empeño de Rodríguez en su carrera. Con gran asiduidad, estudia, dibuja y proyecta; en 1855 ya tiene termina-

5 Manuel Francisco Álvarez, El doctor Cavallari y la carrera de ingeniero civil en México, México, A. Carranza y Comp Impresores, 1906, p. 135. 
do "un proyecto para un palacio y una Cartuja", y ha iniciado la construcción de un monumento, diseño de su maestro Antonio Cípolla, quien se decía arquitecto del reino de las dos Sicilias, y también en ese mismo año, en una carta dirigida a la Academia de San Carlos, informa que piensa restaurar el "Templo de la Fortuna Pranestra, en Palestrina, a 40 millas de Roma, templo grecorromano, importante por su construcción y diversidad de planos geométricos".

$\mathrm{Su}$ actividad es tal que el 6 de julio la universidad romana La Sapienza, le confiere el título de Doctor en Ciencias Matemáticas, lo cual informa a la Academia de San Carlos, en carta fechada el 14 de julio de 1855. Carta que se encuentra consignada en la Guia con el número 5869.6

Sus triunfos no le hacen olvidar a la Academia de San Carlos y en su afán porque los estudios sobre arquitectura mejoren en México, y recordando la iniciativa que había tenido en abril de 1853, pone en contacto al arquitecto Cípolla (quien también fue profesor de los hermanos Juan y Ramón Agea) con la academia. En el apartado 6325 de la Guia aparece el contrato firmado entre Cípolla y la Academia de San Carlos, en el cual el arquitecto italiano se obliga a hacer una colección de diseños arquitectónicos para que sirvan de modelos a los alumnos de la Academia Mexicana. En algunas de las cláusulas consignadas por Eduardo Báez se lee:

La colección quedará formada por 36 grandes dibujos, con las dimensiones, cada uno, de 1 metro de largo por 0.70 metros. En la primera serie de cuadros estarán dibujados y acuarelados las órdenes arquitectónicas griego, romano, pompeyano y del renacimiento en Italia del 1500, copiados de los monumentos más célebres de la antigüedad, y en los últimos seis cuadros se harán varias aplicaciones de estos órdenes en reproducciones de algún proyecto muy sencillo. Para la composición puede el dicho Cípolla valerse de su discípulo Rodriguez... que puede ofrecer varios proyectos sobre varios estilos... Roma 16 de octubre de 1854. Antonio Cípolla (rúbrica) ${ }^{7}$

Entre Cípolla y sus alumnos se había establecido una relación muy cordial. Algunas cartas del arquitecto italiano, al igual que el contrato antes señalado, expresan la confianza del maestro hacia su dis-

- Eduardo Báez Macias, Guía del Archivo de la Antigua Academia de San Car. los (1844-1867), p. 195.

7 Eduardo Báez Macías, op. cit., p. 286 
cípulo, ya que después de diversas consideraciones sobre la enseñanza de la arquitectura, entre otras, "la arquitectura no se puede aprender sin estudiar sus monumentos... Que si los monumentos arquitectónicos se pudieran estudiar en obras publicadas en las que todo estuviera perfectamente dibujado, en este caso sería inútil hacer viajes a Roma". ${ }^{8}$

Cípolla consideraba difícil que algún arquitecto de prestigio aceptara dejar su país y clientela, "a menos que se tratara de un mediocre", y agregaba que en México, pese a que la enseñanza de la arquitectura estaba en una etapa de inmadurez, sabía que "había arquitectos de mérito que podrian dirigir las clases como los hermanos Agea, en conjunto con el mismo Rodríguez, repartiendo entre los tres las cátedras de composición, elementos y arquitectura práctica".

La confianza que Gípolla ponía en sus alumnos resultaba muy importante para Rodríguez, ya que si en la actualidad poco se sabe del italiano, en esos años según consta en el expediente 6683 de la Guia, Manuel Larrainzar, al escribir a Bernardo Couto de la Junta de Gobierno de la Academia, señalaba: "Cípolla en cuyo taller trabajaba Ramón Rodríguez Arangoiti, era el más distinguido arquitecto de Roma".

Rodríguez Arangoiti sigue enviando diseños y dibujos. El 10 de junio de 1855, según se consigna en una carta que envía a la Academia la Legación Mexicana, cerca de Su Santidad, se transcribe el nombramiento de Socio de Mérito conferido a Rodríguez Arangoiti el 10 de junio de ese año por la congregación artística de Roma Virtuosi al Pantheon, por sus planos para una cartuja. ${ }^{9}$

Un año más tarde termina los planos para un palacio y villa de recreoo. En 1857, según el expediente 6140 , recibe 50 pesos para viajar de Roma a París.

De su estancia en París hablan brevemente tanto Manuel Francisco Alvarez como Katzman. Esos años son de igual manera fructiferos para su carrera, ya que como explica Álvarez:

trabajó mucho dibujando para diversas fábricas de objetos de metal; llaman la atención por lo bien dibujados y compuestos, candelabros, fuentes, altares, etc., etc. De su estancia en París, Rodríguez se creó su segunda manera de sentir, el neogreco, que en obras y edificios

8 Eduardo Báez Macias, op. cit., p. 391.

9 Eduardo Báez Macías, op. cit, pp. 360-361. 
se empleaba y se sentía con tanto gusto. Rodriguez trabajó también en las obras públicas de la ciudad de París. ${ }^{10}$

Katzman a su vez dice que en "la Exposición de 1859 en el palacio de la Industria de París, se mostró un proyecto suyo de puerto y escuela de marina de Tehuantepec".

Resulta indudable que Rodríguez conoció la obra del pionero del funcionalismo y controvertido arquitecto. Iabrouste, uno de los primeros en utilizar estructưas metálicas y ornamentación clásica, pues Rodríguez en proyectos posteriores y ya en México se adelanta en muchos años a otros arquitectos, al utilizar el hierro en sus construcciones $y$, sobre todo, en el diseño de los pabellones destinados a albergar exposiciones internacionales.

Pese a que sus biógrafos toman como fecha de su regreso a México el año de 1864, la realidad es que vuelve en 1862, según consta en el archivo de la Antigua Academia de San Carlos, en donde hay con el número 6102, un oficio del Ministerio de Justicia e Instrucción Pública en el que existe la comunicación informando del regreso del alumno Ramón Rodríguez Arangoiti, firmado el 18 de julio de 1862 por Terán.

Las actividades, proyectos, etc., efectuados por Rodriguez Arangoiti no pasaron inadvertidos en su patria, en las exposiciones de San Carlos, continuamente se exhibieron trabajos de él cnviados desde Roma y París, los que fueron favorablemente comentados por la críti. ca, como los expuestos en la muestra 86 de la Academia de San Carlos, de los que el reportero de $E l$ Siglo $X I X$, el lunes 17 de febrero de 1862 , informa:

son como siempre, obras verdaderamente maestras en todos sentidos, considerados como dibujos y lavados; ¡Qué fineza en la delineación! ¿Qué precisión y exactitud hasta en los más finos detalles! iQué gusto en los ornatos! Si entendemos al lavado, veremos una limpieza, una brillantez en el color, una gradación en las tintas tal, que nos hace aproximar o alejar los objetos de una manera sorprendente.

La composición es grandiosa; el efecto sorprendente. El señor Rodríguez ha sostenido muy bien el honor de los pensionados mexicanos en Roma y ahora en París, pues hace tres años que remite de estas capitales de las artes y las ciencias, trabajos de un mérito extraordi-

10 Manuel Francisco Álvarez, op cit., p. 129. 
nario, no sólo por las galas de la composición, sino por la belleza de la ejecución. El señor Rodríguez debe volver muy pronto a su patria, tan vilipendiada por mordaces y ridículos parlanchines como el ex embajador español don Joaquín Pacheco, y creemos que será uno de los que con sus conocimientos y trabajos, pueda dar un solemne mentís a los que la calumnian, diciendo que [México] es incapaz de alcanzar el grado de adelanto en que se encuentran las naciones europeas. ${ }^{11}$

Las experiencias y talento de Rodríguez le valen una cátedra en la Academia de San Carlos, la que al mismo tiempo le extiende una autorización para que pueda ejercer su profesión en el Imperio de Maximiliano. En 1865 aparece como director de la Dirección General de Obras de la Casa Imperial. En el mismo año, el 19 de abril, gracias a un informe solicitado a la academia por el Ministerio de Instrucción Pública y Cultural, se avisa que este arquitecto devenga un sueldo anual de mil doscientos pesos. En 1866 la Academia le dice al mismo ministerio que Rodríguez Arangoiti tiene a su cargo las cátedras de Geología y Mecánica Aplicada, y agrega que vive en la calle de San Francisco núm. 6.

Manuel Francisco Álvarez y Katzman publican un listado de las obras y proyectos efectuados por Rodriguez, entre otras, las más im. portantes son:

proyecto para un monumento a la Independencia en la Plaza Mayor en 1864; diseños para un monumento a Colón; Transformaciones en el Palacio Nacional y en el Alcázar de Chapultepec; el Palacio de Justicia en Toluca (1869-1870); Catedral de Toluca (proyecto e iniciación (1870), etcétera.

Los dos últimos edificios, al igual que la parroquia de San José de Iturbide, son clasicistas y en ellos está plasmada su formación y preferencia por el repertorio formal grecorromano, pero ya pasado por el tamiz renacentista.

Es importante hacer hincapié en que así como Álvarez y Katzman reconocen eĩ mérito de este diseñador y constructor, que en San José de Iturbide "demuestra ser uno de los mejores arquitectos clásicos".

11 Ida Rodríguez Prampolini, La critica de arte en México en el siglo xix, do. cumentos II (1858-1878), México, UNAM, I.IE 1964 (Serie Estudios y Fuentes del Arte en México, xvir). 
El cuidado que los promotores de esa obra tuvieron en dejar constancia de quienes laboraron en ese edificio, otorga también mérito al notable artesano Valentín López, lo que es poco usual, ya que son raras las referencias a esos anónimos trabajadores y no por anónimos menos dignos de reconocimiento.*

\section{APÉNDICE}

fábRICA DE mosaicos de cemento (etc.) Álvarez Hermanos, Sucr. Querétaro, marzo 18-1925. Sr. Cura Pbro. D. Fernando Núñez. Curato. S. José Iturbide, Gto. Muy estimado señor y amigo:

Tengo el gusto de acompañar a Ud. el estudio e informe relativo a los desperfectos que se observan en el pórtico del templo de San José Iturbide que es al digno cargo de Ud., así como los medios para su reparación. Sírvase Ud. aceptar este pequeño trabajo como muestra de mi estimación. Soy de Ud. afmo. amigo y atto. S.S. Sal. vador Alvarez (rúbrica).

\section{Informe sobre la parroquia}

Estudio practicado por el suscrito Ingeniero, sobre las condiciones en que se encuentra el peristilo o pórtico del Templo de San José Iturbide, Gto. y de las obras de reparación del mismo.

Por el examen detenido de las columnas que soporta el entablamiento y frontón, así como de la bóveda plana del pórtico y muro frontal del templo, resulta lo siguiente:

$1^{\circ}$. Las ocho columnas sin excepción, presentan en diversas partes importantes fallas, bajo la forma de trozos desprendidos de los fustes y basamentos y grietas en el sentido vertical; las dos columnas de la izquierda están cinchadas con fierro cerca de la base para evitar su total ruina.

$2^{\circ}$. La bóveda plana que cubre el peristilo presenta juntas muy abiertas en algunos puntos con desprendimientos de la argamasa que las llenaba.

$3^{\circ}$. El muro frontal del templo, en la parte que se eleva sobre el cerramiento de la puerta central, acusa deterioro de las piedras que lo forman ocasionado por el descenso mismo de las dovelas del cerramiento.

* Se adjunta como apéndice el informe sobre el estado de conservación de la parroquia en 1925, y los costos de reparación de la misma dados por el ingeniero Salvador Alvarez. 
$4^{\circ}$. Por último, en las bóvedas alta y baja del coro se notan algunas cuarteaduras.

La cantera es mala porque no es uniforme y es blanca y está sobre todo llena de cruceros o planos de exfoliación.

La construcción es viciosa porque al cortar los tambores de las columnas, no se tuvo en cuenta el lecho de cantera o sea el sentido de la estratificación y en todas las piedras que han hallado el lecho de cantera es vertical. En la bóveda del peristilo se hizo uso de dovelas excesivamente angostas resultando un número exagerado de juntas y el corte de dichas dovelas no es muy exacto; probablemente este último defecto se subsanó poniendo demasiada mezcla en las juntas.

El aparejo de cerramiento de la puerta adolece del mismo defecto, el gran número de dovelas angostas de corte imperfecto.

Por último, las cuarteaduras de las bóvedas del coro, se deben al pequeño sentamiento de las columnas del peristilo y al coceo de la bóveda baja del coro.

Debo hacer constar que aunque los hechos anotados son de importancia y merecen preocuparse por ellos para la restauración del templo, sobre todo por lo que empañan su belleza, las reparaciones no son de carácter urgente, pues según parece, estos defectos se produjeron desde hace mucho tiempo determinándose un estado de equilibrio en los esfuerzos que obran en las distintas partes afecta das de la construcción y el mal ha quedado estacionario. Yo mismo recuerdo que en el año de 1913 , que por primera vez conocí ese templo, ya se encontraba en idénticas condiciones y por lo tanto estimo que no seguirán acentuándose de un modo sensible.

\section{Plan de reparaciones}

PERISTILO. La parte más delicada y costosa es sin duda la sustitución de las columnas. Esto debe hacerse una por una sucesivamente, valiéndose de dos torres portátiles construidas con fiexro y madera, según la idea que contiene el croquis adjunto, estas torres soportarán provisionalmente la parte del entablamiento que corresponde a la columna que se cambie; para ello se instalarán las torres en los huecos correspondientes de intercolumnio recibiendo el lecho bajo del arquitrabe entre las columnas y la piedra de arquitrabe, que forma salmer y que reposa directamente sobre la columna por medio de dos puentes en la disposición ilustrada en el croquis No. 2. Hecho ésto se romperá el tambor que está inmediatamente abajo del capitel y se salvará esto; después de quitar el resto de la columna se procede a colocar la nueva, terminándola con el mismo capitel antiguo (todos están utilizables).

Las nuevas columnas pueden hacerse de cantera si se encuentra 
de buena calidad y resistencia, o bien de piedra artificial con núcleo de cemento armado. Bajo el punto de vista artístico es preferible lo primero, si se atiende a la seguridad es preferible lo segundo.

Terminado el cambio de las columnas se procederá a arreglar los desperfectos de la puerta y muro frontal, para lo cual bastará poner un umbral bajo el cerramiento y forzar éste hacia arriba por medio de puntales y gatos, después de haber limpiado las juntas abiertas, para que todas las piedras vuelvan a su posición correcta, rellenando las juntas con morteros de cemento. Pasado un tiempo prudente se quitará el apuntalamiento.

Para arreglar la bóveda plana del peristilo bastará limpiar y revocar las juntas abiertas.

En cuanto a las cuarteaduras interiores del templo estimo suficiente acuñarlas y lechadearlas con cemento.

Es algo difícil entrar en consideración del costo de estos trabajos, por no haber datos exactos sobre la cantera, pero a título de aproximación, estimo que cada columna podrá costar $\$ 500.00$ y otros $\$ 500.00$ las demás reparaciones, además, el arsenal necesario para las maniobras, materiales secundarios y mano de obra importarán como $\$ 7,500.00$ más los honorarios de la persona que dirija la obra. (Aproximadamente $\$ 15.000$ todo.)

Querétaro, marzo 19-1925. Salvador Álvarez (rúbrica).

(Copió EM de los documentos originales, proporcionados por don Fìliberto Núñez Olvera.)

Nota: estas obras de reparación quedaton pendientes parque el mismo año de 1925 ó 26, sobrevino el conflicto religioso que clausuró los cultos hasta el año 1928 ó 29; y después se perdió el interés seguramente o se olvidó el problema, pues el costo nunca ha sido obstáculo para este tipo de obras. Aunque ia situación estacionaria del mal - como dice el ingeniero Alvarez_, se ha prolongado 50 años más, conviene que no seamos ciegos a la necesidad de esa reparación del templo, que hoy natuxalmente costará diez veces más y acaso se haya agravado

Recordemos además que el señor Servín Lozada se quejaba de que faltara en el pueblo entusiasmo para completar la estatuaria, _ serán las seis de los nichos de la fachada, dos de los nichos del pórtico-, y la decoración interior del templo (que no sabemos en qué pueda consistir aparte de la pintura). Algo más importante que eso - nos parece_-, es poner el barandal o enrejado que nunca ha tenido, lo cual, al cerrar Ia explanada, le dará perspectiva a su posición elevada; y de paso tendrá el conjunto un toque final de cosa acabada, que realzaría su digna belleza. 


\section{BIBLIOGRAFIA}

ÁLvarez, Manuel Francisco, El doctor Cavallari y la carrera de ingeniero civil en México. México, A Carranza y Comp. Impresores, 1906.

BÁez Macías, Eduardo, Guía del Archivo de la Antigua Academia de San Carlos (1841-1843). México, UNAM, I.IE, 1972 (Serie Estudios y Fuentes del Arte en México, xxxi).

Báez Macías, Eduardo, Guía del Archivo de la Antigua Academia de San Carlos (1844-1867). México, UNAM, I.I.E., 1976 (Estudios y Fuentes del Arte en México, xxxv).

Katzman, Israel, Arquitectura del siglo xix en México. México, UNAM, CIA, 1973.

Rodriguez Prampolini, Ida, La critica de arte en México en el siglo xix. Documentos II (1858-1878). México, UNAM, I.I.E., 1964 (Serie Estudios y Fuentes del Arte en México, xvir).

Romero DE Terreros, Manuel, Catálogos de las exposiciones de la antigua Academia de San Carlos de México (1850-1898). México, UNAM, I.I.E, 1963 (Serie Estudios y Fuentes del Arte en México, xIv). 